\title{
Traumatism Risk Reduction by Means of Technologies of Continuous Development of Workers' Competency in Occupational Safety
}

\author{
Yuri Ivanov ${ }^{1}$, Anatoly Fomin ${ }^{2,3, *}$, Aleksey Voroshilov ${ }^{4}$, and Gennady Sedelnikov ${ }^{4}$ \\ ${ }^{1}$ JSC «SUEK-Kuzbass», 6525071 Vasilieva st., Leninsk-Kuznetskiy, Russia \\ ${ }^{2}$ T.F. Gorbachev Kuzbass State Technical University, 65000028 Vesennya st., Kemerovo, Russia \\ ${ }^{3}$ JSC NC VOSTNII, 6500023 Institutskaya st., Kemerovo, Russia \\ ${ }^{4}$ Kuzbass-COT LLC, 650002 Kemerovo, Russia
}

\begin{abstract}
The article is dedicated to the video informational technologies of continuous development and control of workers' competency in occupational safety, providing significant reduction of occupational traumatism in coal mining industry. Most modern approaches to develop workers' competency are based on the technologies, providing maximal memorization of study materials and efficient forming of initial working skills and safe work experience. Some examples of use of the technology, as well as practical results for 2014-2017 in JSC "SUEK-Kuzbass". Key words: coal mining industry, traumatism, occupational safety, occupational safety training, competency, occupational risks.
\end{abstract}

\section{Introduction}

The coal industry of Russia is represented by mines, open pits, processing and briquette factories. This industry belongs to hazardous production facilities, where governmental inspection institution (Rostechnadzor) monitors the state of accidents and industrial injuries.

The most frequent accidents at coal industry enterprises are caused by methane and coal dust explosions, fires, landslides and collapses in mines. At the same time, the overwhelming proportion of fatal accidents occurs during underground work in mines. The main causes of accidents include the following:

- violation of technological and production discipline,

- lack of control over compliance with safety regulations,

- low skill level of workers.

The workers in the underground coal mine face serious problems in terms of emergency preparedness, despite the fact that they have undergoing training, and the organization and activities of the mine rescuers meet modern requirements. Miners recognize the need for training in emergency situations in a simulated environment.

\footnotetext{
*Corresponding author: fominai@kuzstu.ru
} 


\section{Material and Methods}

Studies on occupational traumatism analysis in different countries show the main causes of $70-90 \%$ of occupational accidents are workers' incompetent actions. That is why new approaches to assess traumatism risks, caused by incompetent workers actions, are being developed worldwide. As an example we can mention programs by ISSA Mining "Occupational accidents prevention, the Vision Zero Prevention Strategy" and "7 Golden rules for Safe Mining", MSHA Program (US Occupational Safety and Health Administration for Mining) [1-4].

In accordance with the laws, MSHA is responsible for approving training programs for mine workers, propaganda safety rules, appropriate rescue training, as well as for the approval of technological devices used underground, and the inspection of coal mines at least four times a year. The National Institute for Occupational Safety and Health (NIOSH) separates some of the responsibilities for improving the safety of mining work. It investigates the causes of occupational diseases and injuries associated with working in a mine, develops and tests new technologies and equipment aimed at improving safety, and recommends safety and health standards.

In addition, in many states there are mine safety agencies that conduct regular checks on the observance of regulations and orders, and in many states they perform daily monitoring of mine safety regulations. In response to concerns over the safety of coal mines, caused by an increase in accidents, NIOSH researched several aspects of safety in coal mines:

- the problems associated with preparing for emergency situations,

- how well MSHA provides for the training of mine workers;

- how effectively MSHA is coordinating their efforts to review and approve measures that contribute to a more efficient functioning of the mine safety system;

- what civil penalties apply in case of violation of safety and health regulations.

Concerning the workers' competency in occupational safety in the USA, MSHA provides some materials for practical use, for example, a guide to using a self-rescuer, but the miners have neither the information nor the conditions for conducting trainings in simulated emergency situations. The results of the study also show that $77 \%$ of the mines conducted evacuation trainings in 2006, in which the miners practiced putting on selfrescuers [2]. However, due to the fact that the new US rules, issued in December 2006, require that trainings are held annually, many mines do not conduct them due to limited resources. As a result, they will need new rescue teams that need to be created and trained. For training, appropriate resources are needed to simulate various emergency situations in the mine. Therefore, in the USA, MSHA systematically informs mines about the availability of such resources and equipment. In addition, MSHA periodically reviews and updates this information. The US Department of Labor also obliged MSHA to tighten control over training. This control includes:

- revision and standardization of the procedure for approving new instructors in all regions; - systematic professional development of instructors in order to continuously improve their knowledge and skills;

- improved reporting system;

- development of a miners' training monitoring process and a training effectiveness assessment system, which includes an assessment of how effectively the training is conducted, the assigned tasks are carried out, and feedback is provided to the instructors.

As a rule, modern approaches to develop workers' competency are based on the technologies, providing maximal memorization of study materials and efficient forming of initial working skills and safe work experience [5,6]. However overwhelmingly these are full-time trainings in specialized training centers, and when the workers get back to work their education is practically ceased. 
Moreover, the implementation of new modern technologies, mining equipment, machines, materials outpaces previously completed educational programs. That is why technological progress, providing the development and the improvement of production, requires synchronous and continuous development of workers' competency in occupational safety directly in mining enterprises.

Foreign press notes that in comparison with other economic sectors in many countries mining industry is one of the most hazardous, where most injuries are multivariate, and occupational risks can be potentially decreased by means of enhancing working conditions and increase of workers' competency [7-9].

The article is dedicated to one of the attempts to organize workers' trainings directly in the working place by means of developed by "Kuzbass-COT" "Video informational complex for development and control of workers' competence according to the Occupational Safety requirements" (Complex). The Complex was first implemented in JSC "SUEK-Kuzbass" enterprises.

\section{Studies' results}

Generally, the Complex is a software and training platform, intended for accelerated construction a wide range of applied training programs for particular enterprises to provide massive and timely workers' trainings on safe methods of work and to form the stereotypes of safe behavior.

The main objective of the Complex is to reduce workers' injuries caused by their incompetent actions during the execution of mining technological operations.

The defined objective is achieved through every worker's before-the-shift expresstraining.

\subsection{Before-the-shift express-training}

Let us consider the procedure of before-the-shift express-training more in detail.

Before the shift the worker by means of terminal is asked a question, concerning his profession, which he has to answer by choosing one of three proposed versions.

If the worker choose incorrect version he's demonstrated probable consequences of his unsafe actions, including probable injuries, and he's given the right version. Thus, the competency is being corrected.

The question is repeated.

If the worker choose correct version he's demonstrated the dangers, he could avoid by answering correctly. This is a kind of hidden compliment.

\subsection{Complementary express-training}

The workers, who have low progress, are monthly directed to complementary express training, consisting of 5 questions.

After a long absence from work the worker is assigned a task to choose the right sequence of actions, which ends by memorization sequence.

The workers, who violate discipline at work, are assigned 5 tasks, concerning incident analysis or shocking video.

Table 1 shows the statistics of injured number distribution in JSC SUEK-Kuzbass. It includes both enterprises, where the Complex has been installed in the beginning of 2015, and enterprises, where the Complex has not been installed and before-the-shift expresstrainings have not been held. 
Table 1. Statistics, describing traumatism in JSC "SUEK-Kuzbass" for the period of 2014-2017.

\begin{tabular}{|l|c|c|c|c|}
\hline \multicolumn{1}{|c|}{ Years } & $\mathbf{2 0 1 4}$ & $\mathbf{2 0 1 5}$ & $\mathbf{2 0 1 6}$ & $\mathbf{2 0 1 7}$ \\
\hline Number of injured miners & 32 & 22 & 13 & 12 \\
\hline $\begin{array}{l}\text { Enterprises, where the Complex has } \\
\text { not been installed }\end{array}$ & 11 & 5 & 10 & 12 \\
\hline
\end{tabular}

As in enterprises where the Complex had been installed worker's competency grew up, the occupational traumatism began to decrease sharply, while in other enterprises the traumatism did not change significantly. It proves the Complex influences the traumatism independently and significantly.

Nowadays the Complex operates in 8 companies in 36 production units. In the enterprises JSC "SUEK-Kuzbass" alone there were held more than 3 millions expresstrainings.

Using the relation between unsafe workers' actions and traumatism, as well as a combination of "Probability Harm Risk (PHR)" methodology with other recognized methods of risk assessment, Kuzbass-COT has developed the methodology of quantitative assessment of occupational risk of traumatism, caused by workers' incompetent actions.

Nowadays AO "SUEK-Kuzbass" as a matter of risk-oriented approach establishment has approved the Regulation "Competency control and management of occupational traumatism risk, caused by incompetent workers' actions" and now implement it not only in coal mining industry enterprises (coal mines, open-cast coal mines, concentrating factories) but in the other economical sectors of Russia.

The Complex on a monthly basis informs workers, managers at all levels about competency status, occupational risks at different levels: worker's, production area, and the whole production unit. For example, a head of production unit among the other receive the graph of changes in monthly predictive number of injured for the current year.

Let us consider in detail the information, provided at worker's level in the beginning of every month during the before the shift express-training:

1. Graphical information demonstrating his competency level and his occupational risk level for the previous 6 month.

2. Worker's competency relative level expressed as a percentage and the information to what extent his personal occupational risk is higher or lower than acceptable risk level.

3. Appropriate recommendations and advice to help him increase his own competency.

As practice shows, when a worker realizes that his personal risk is $10-50$ times higher than acceptable risk level, his actions become more meaningful and safe.

Nowadays the methodology of quantitative assessment of occupational risk of traumatism caused by workers' incompetent actions is implemented in 4 large mining enterprises.

\section{Discussion}

The results demonstrate that the use of computer training programs let organize massive and continuous training for workers on safe behavior during work, it leads to significant decrease of casualties and injuries number in mining enterprises. It probably comes at the expense of forming the stereotypes of safe behavior and work in hazardous production unit. Risk-oriented approach to assess workers' competency is high-potential. Actually, if we have monthly predictive number of injured we can take timely and efficient managerial decisions, directed on risk reduction, occupational accidents prevention in mining. 


\section{Conclusions}

1. Video informational Complex provides continuous development and control of workers' competency in occupational safety that eventually leads to significant decrease of traumatism level.

2. Quantitative assessment of occupational risk of traumatism caused by workers' incompetent actions let take timely managerial decisions, directed on reduction of traumatism and occupational accidents risk in coal mining industry.

\section{References}

1. K. Amponsah-Tawiah, J. Mensah, SHAW, 7, 225-230 (2016)

2. S. E. Verra, A. Benzerga, B. Jiao, K. Ruggeri, SHAW, 10, 21-29 (2019)

3. S. K. Kang, SHAW, 10, 1-2 (2019)

4. A. Barkhordari, A. Dehghani, A. Kianfar, S. Mahmoudi, F. Aminifard, SHAW, 1, 49-59 (2015)

5. Y. Sun, M. Arning, F. Bochmann, J. Börger, T. Heitmann, SHAW, 9, 140-143 (2018)

6. B. Cirjaliu, E. M. Boatca, A. Gaureanu, H. Weinschrott, TIIM Joint International Conference Proceedings, 1, 1069-1076 (2015)

7. S. Onder, Safety Science, 59, 86-92 (2013)

8. P. A. Schulte, S. Pandalai, V. Wulsin, H. K. Chun, AJPH, 3, 434-448 (2012)

9. D. I. Swedler, S. K. Verma, Y-H. Huang, D. A. Lombardi, W-R. Chang, M. Brennan, T. K. Courtney, OEMED, 72:7, 1-6 (2015)

10. V. Falco, TIIM Joint International Conference Proceedings, 1, 455-461 (2015) 